\title{
Egypt's Science and Technology Parks Outlook : A Focus on SRTACity (City for Scientific Research and Technology Applications)
}

\author{
Yasser R. Abdel-Fattah, * Abdel-Hady B. Kashyout, and Walaa M. Sheta \\ Supreme Council for Research Centers and Institutes, Ministry of Scientific Research, Cairo, Egypt. City for Scientific Research and Technology \\ Applications (SRTA-City), New Borg El-Arab City, Alexandria, Egypt.
}

\begin{abstract}
Egypt has been known as the light house of science and innovation not only in the Middle East but to the world across ages. Recently, there have been many ups and downs that positioned Egypt in a lower rank that it actually deserves according to its long history. This review entitles the current condition of science, technology and innovation in Egypt and the consequent setting up of best practices of science and technology parks (STPS) experiences. Egypt's science, technology and innovation (STI) system is highly centralized and dominated by the public sector, with R\&D happening mostly in state-run universities and research centers supervised by the Ministry of Higher Education and Ministry of Scientific Research. R\&D indicators state that Egypt ranking is 40th worldwide for the published articles (around 10,000 papers in 2011), while the numbers of issued patents (350 local and 50 international in 2011) is still far beyond expected. STPs in Egypt are addressed in this review by three examples; smart village in Cairo, Investment zone in Borg El-Arab City and Technology Valley in Ismailia. The three models are discussed in details and a suggested road map for developing more STPs is estimated.
\end{abstract}

\section{INTRODUCTION}

Many developing countries have recognised the need to adopt a long term economic strategy that shifts some of its focus to developing a more extensive knowledge based economy. To achieve this, it requires planning at a national level in order to create the right environment in which to integrate the supply of knowledge that derives from investment of national resources in science, technology and education, with demand and to stimulate business and government to utilise the knowledge output and drive this up the commercial value chain.

*Correspondence to : Dr. Yasser R. Abdel-Fattah

Supreme Council for Research Centers and Institutes, Ministry of Scientific Research, Cairo, Egypt.

E-mail : vasser1967@yahoo.com

World Technopolis Review

Copyright $\odot$ World Technopolis Association

cC This is an open-access article distributed under the terms of the Creative Commons Attribution Non-Commercial License(http://creativecommons.org/icenses/by-nc/3.0) which permits unrestricted noncommercial use, distribution, and reproduction in any medium, provided the original work is properly cited
Building a knowledge based economy requires both a relevant supply of technology and demand for this from industry and other customers including government. In some countries there are weaknesses on both sides of this supply and demand relationship as well as at the interface between the two. It is now widely understood that the greatest chance of success in developing these connections on a broad front needs the cooperation between the three stakeholder groups of government, higher education and business. One strategy adopted to create better connections between business and higher education has been to develop science and technology parks.

Evidence from international experience shows that the most successful science and technology parks are those which capitalize on existing location factors which influence the capacity for generation of knowledge capital, the capacity to actively engage with this output and the creation of new technology and products (includes services) that find a market. To do this requires scientific and technological competence, relevant social and human capital that can exploit this, markets for the outputs and the right physical facilities 
in which these linkages can be fostered and developed. Important physical factors in starting this cycle of generation are the role of a high-grade university, the location of a variety of research facilities, the attractiveness of the area to highly-qualified workers and entrepreneurs as a place to live and work and easy access to major cities by an efficient transportation network.

The optimal set of components for successful science and technology parks include, as a central component, a university or research centre that provides both the necessary qualified staff and the basic R\&D, accommodation for commercial activities, access to technical facilities and support services which focus on giving commercial advice to the companies that locate on the site. In some instances where university facilities are not close enough to where a science and technology park is being planned an alternative has been to locate a research institute on the site as an initial focal point for R\&D which can then be developed into a stronger network with other universities and research centres in the region. However, it is also important that in creating these links production capacity is also developed and protected.

In a wider urban planning context it is important that consideration is given to developing a high quality environment in order to improve recruitment and retention of the necessary high-qualified workers and entrepreneurs that are attracted to the site.

The current policy framework in Egypt, which also has ministerial support, is favourable for the creation of a number of science and technology parks. That is, there is a fund to support technology transfer, there is a commitment by government to support a range of emerging important areas of scientific research, and a commitment by government to help to modernise the Egyptian industrial base. This is additionally supported by the existence of high numbers of graduates, recognition that there is a need for change and an emerging interest by business in establishing higher value products and services that will help them to modernise and find new markets.

A number of early science and technology park initiatives are already underway in Egypt and there is also some longer term planning taking place for others that will build on the initial experience of the earlier projects. These projects are being led by the central government.

A report of UNESCO on the proposal for a pilot Science Park in Egypt suggested that the science and technology park development programme in Egypt should emphasize links between research and production. One strategy to achieve this is to locate high-tech industrial parks next to the proposed science and technology parks so that the option exists to first attract industrial plants to create an agglomeration of industrial activities. It is therefore recommended that this strategy is adopted for the development of the initial science and technology parks in Egypt. This is suggested because of the need to create industrial activity as a pre-cursor to high-tech development.

\section{EGYPT: LAND, PEOPLE AND ECONOMY}

Egypt, the historically ancient country stands out as a flag bearer of the civilization known for its scientific and cultural heritage. Contributions by the Egyptian scientists, researchers and thinkers in the fields of astronomy, mathematics, medicine, philosophy and architecture span over centuries, with the pursuit of knowledge receiving further impetus following the advent of Islam in the $8^{\text {th }}$ century.

The regularity and richness of the annual Nile River flood, coupled with semi-isolation provided by deserts to the east and west, allowed for the development of one of the world's great civilizations. A unified kingdom arose circa 3200 B.C., and a series of dynasties ruled in Egypt for the next three millennia. A local military caste, the Mamluks took control about 1250 and continued to govern after the conquest of Egypt by the Ottoman Turks in 1517. Completion of the Suez Canal in 1869 elevated Egypt as an important world transportation hub. Ostensibly to protect its investments, Britain seized control of Egypt's government in 1882, but nominal allegiance to the Ottoman Empire continued until 1914. Partially independent from the UK in 1922, Egypt acquired full sovereignty from Britain in 1952. The completion of the Aswan High Dam in 1971 and the resultant Lake Nasser have altered the time-honored place of the Nile River in the agriculture and ecology of Egypt. A rapidly growing population (the largest in the Arab world), limited arable land, and dependence on the Nile all continue to overtax resources and stress society. The government has struggled to meet the demands of Egypt's population through economic reform and massive investment in communications and physical infrastructure. Inspired by the 2010 Tunisian revolution, Egyptian opposition groups led demonstrations and labour strikes countrywide, culminating in President Hosni Mubarak's ouster. Egypt's military assumed national 
leadership until a new parliament was in place in early 2012. The same year Muslim Brotherhood candidate, Mohammed Morsi, won the presidential election and a new constitution was affirmed by the end of 2012 .

Egypt is one of the most leading industrial countries in Africa and in MENA region, with GDP real growth rate of $2 \%$ as an estimate of 2012 in comparison with $4.7 \%$ in 2009 according to CIA World Fact book. The GDP composition by sectors if as follows; Agriculture 14.7\%, Industry 37.4\%, and Services $47.9 \%$ (2012 estimate) with 27.24 million work force where the unemployment rate remains at $12.5 \%$. The distribution of labour force across the sector is as follows: Agriculture 32\%, Industry 17\% and Services 51\%. The major industries are Textiles, Food Processing, Tourism, Chemicals, Pharmaceuticals, Hydrocarbons, Construction, Cement, Metals and Light Manufactures with Industrial Production Growth Rate of 5.1\%.

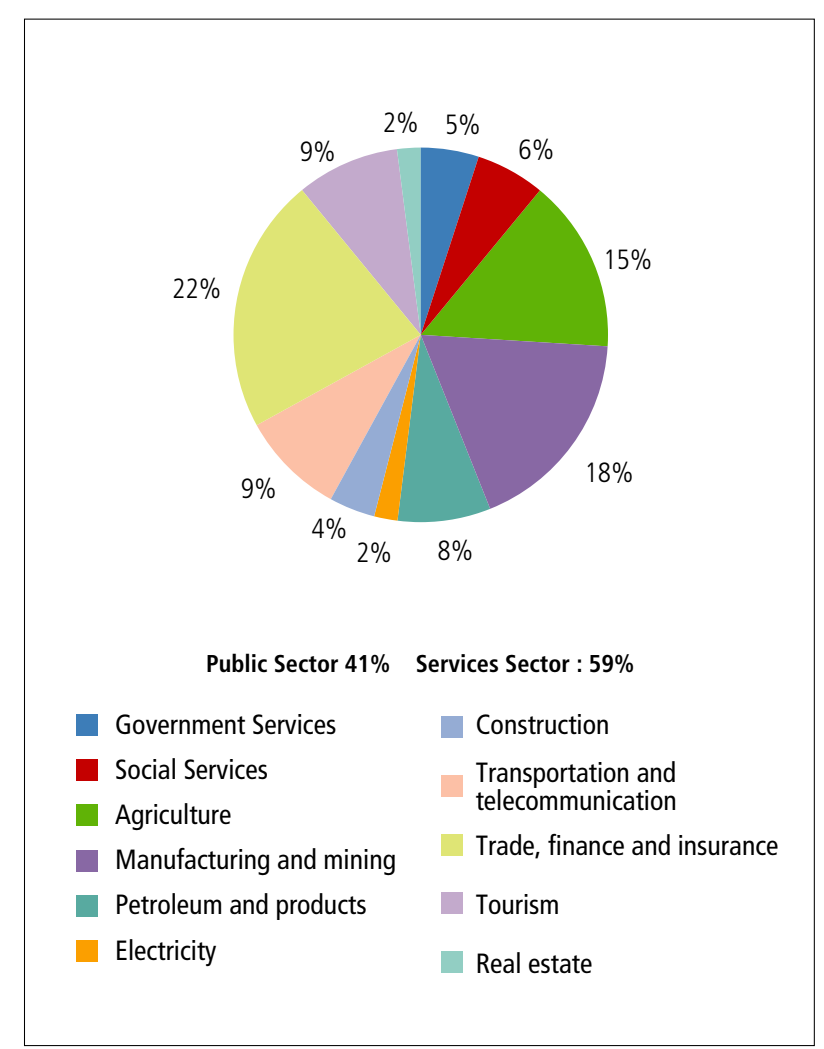

Fig. 1. Egypt Statistics: GDP per Sector

It is still, however, with very limited investments, Egypt can exploit its best asset, which is its youth, given that more than half of Egypt's population is below the age of thirty. Egypt can fill the technological and communications gap faster than could be imagined. Egypt is having demographic dividend where $62.8 \%$ of the population falls within $15-64$ years age group with a median of 24 years (male 23.8 years, female 24.3 years). About $58 \%$ of the Egyptian population is under the age of twenty five, and more than 16 million young Egyptians are currently enrolled in primary, secondary and technical education.

\section{CURRENT STATUS OF EGYPTIAN INNOVATION}

There is no question that Egypt's research community which today numbers some 120,000 theoretical and applied scientists in 23 government universities and 198 research centers has always harbored great talent.

According to the most commonly used measure of scientific performance - the number of papers published in scientific journals - early indications are positive. Egypt's output rose from 4,922 publications in 2006 to 10,295 in 2011 (according to the SciMAGO SCOPUS database of country rankings), with notable improvements in agricultural sciences, engineering, computer science, medicine and biochemistry, genetics and molecular biology 13 . Over the same period its global share of publications rose from $0.27 \%$ to $0.44 \%$, and its regional share from $8.14 \%$ to $9.17 \%$.

In 2011, Egypt ranks fourth behind Iran, Turkey and Israel $\left(17,19\right.$ and $27^{\text {th }}$ global ranking; respectively) among OIC and Middle Eastern countries on numbers of papers published, yet lies $40^{\text {th }}$ globally, with Harvard University alone publishing twice as many. When you consider the number of papers published per million population, Egypt still looks uncompetitive next to some Middle Eastern countries, and markedly so next to economically advanced countries such as Finland and Korea. However there are clear signs that the quality of its research is improving. Since the early 1990s its impact factor - derived from the number of times a paper is cited in referenced articles - has risen from a quarter to half the world average.

It is, however, worthy to mention that of the many extraordinary events and behaviors on display during the 18 days in January and February 2011 that led to the overthrow of former president Hosni Mubarak, one thing that consistently stood out was the ability of the protestors to innovate. When 
the regime shut down cell phone networks and the internet, they passed on satellite news broadcast via radio and distributed leaflets to keep the information flow going. They poured soft drinks on their faces to protect themselves from the effects of teargas. They even managed to neutralize the army by befriending them and making them part of the protests.

"Scientific research in Egypt, which was ahead of South Korea, has now fallen to the tail of global rankings over the 30 years of the regime's governance," wrote the Nobel-prize winning chemist Ahmed Zewail in an editorial in the International Herald Tribune in February 2014.

Which Korea Egypt ends up emulating will depend to a great extent on how much it spends on $R \& D$ - generally a good measure of how much faith a government has in scientific research as an engine of development. Between 2004 and 2010 governmental R\&D expenditure averaged around $0.25 \%$ of GDP. Recently, after revolution, much concern was drawn to the expenditure on R\&D expressed by the increase of budget to $0.8 \%$ and the substantial increase in staff members of universities and research centers salaries as an attempt to stabilize the community of innovation in addition to working in more legislative issues to promote investments based on innovation.

\section{EGYPTIAN SCIENCE, TECHNOLOGY AND INNOVATION SYSTEM}

Egypt's STI system is highly centralized and dominated by the public sector, with R\&D happening mostly in state-run universities and research centers supervised by the Ministry of Higher Education and Ministry of Scientific Research (which recently promoted from a state ministry to a ministry with full portfolio). The MOSR, in collaboration with Academy of Scientific Research and Technology (ASRT), is responsible for the national research policy and the research strategy at the country's public universities and research institutes. Egypt's research centers, which used to be scattered across different ministries, are currently being reorganized under the umbrella of the MOSR's Supreme Council of Scientific Research Centers and Institutes, which should ensure their activities are more harmonized.

Over the past four decades, Egypt's Academy of Scientific Research and Technology (ASRT) has been largely responsible for shaping the country's science and innovation system. The academy was founded in 1972 as a non-profit organization affiliated to the Ministry of Scientific Research, responsible for drawing up STI strategies to tackle Egypt's problems and assessing their impact and plays a central role as a think tank and policy adviser to the Ministry of Scientific Research.

Back to 2007, a reform of STI system in Egypt has been carried out starting from reviewing the actual STI infrastructure; looking at the ways other countries managed their research sectors and devising a model of organization and funding that puts education and scientific research at the heart of development.

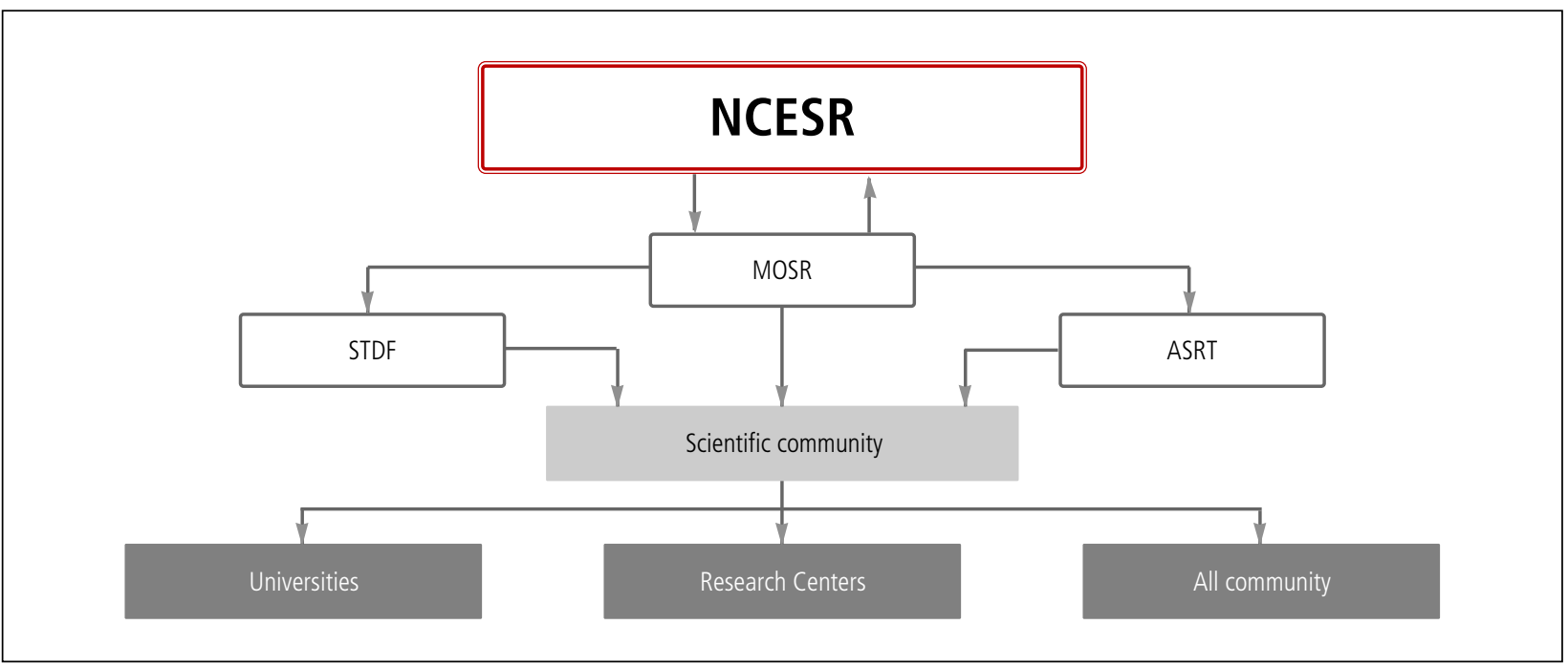

Fig. 2. Current Structure of STI System in Egypt after Restructuring 
The reforms led to a significant change in the way the country's STI system is structured see $<$ Fig. $2>$. The new system is built on several pillars:

- The National Council for Education and Scientific Research (NCESR) which is replacing The Higher Council for Science and Technology. A panel of ministers and nongovernmental experts (including expatriate scientists), re-elected every three years, whose remit is to determine Egypt's developmental priorities and how they should be supported by education and science.

- The Science and Technology Development Fund (STDF), a competitive peer-review grant-awarding scheme that was modeled on Germany's DFG and is now the main funding mechanism in all research disciplines in Egypt, having taken over this role from the ASRT. It has been widely welcomed by researchers. Since its inception in 2008 up to the end of 2010 it had given out LE500 million in grants, which researchers must apply for online. It was due to distribute LE200 million in 2012. 11.

- The Research, Development and Innovation (RDI) programme, a separate funding stream, designed to encourage applied research that is useful to industry. Backed by EUR 31 million from the EU between 2007 and 2015, it supports the development of ideas from drawing board to commercial product, as well as increasing cooperation between researchers and those in industry and promoting the culture of innovation in schools and society. An important component is a network of focal points throughout universities and institutions which provide guidance to researchers wishing to apply for grants from the RDI or other EU funds, such as the Seventh Framework Programme (FP7), the EU's main instrument for funding research between 2007 and 2013.

- A programme of international collaboration known as the Decade of Science, which involves building links with a different country each year between 2007 and 2016, including establishing joint research funds, boosting academic integration and developing centers of excellence. Partners so far include Germany, Japan, Italy, France and the US. 12.

Despite the inevitable political uncertainty since the ousting of Mubarak, the Ministry of Scientific Research under first H. E.
Prof. Amr Salama, Motaz Khorshid (former ministers of scientific research) and then $\mathrm{H}$. E. Prof. Nadia Zakhary put forward several additional proposals that should further improve the prospects for research and innovation in Egypt. These include plans to:

- increase the salaries of researchers at government universities and research centers including adding quality of performance bonuses for all grades.

- employ extra graduates as researchers. Most of these will work at government universities and research institutes, increasing the state research workforce from 98,000 to 130,000 over the next few years.

- harmonize the organization of publicly funded research centers so they are all affiliated to the MOSR (see section 1.3 above).

- developing 25 center of excellences in different fields to have an instant effect on citizens.

- make governmental sources of research funding available to private universities for the first time.

- setting a law for promoting scientific research employed in different ministries as well as private sector to encourage investments.

- increase the number of papers by Egyptian researchers published in international journals to 30,000 a year from the current level of 10,000 a year.

All these reform measures are geared towards supporting Egypt's national programme of research, which is focused on seven areas considered essential for development:

- renewable energy (solar and wind)

- water management (including desalination, more efficient irrigation and new sources of groundwater)

- food and agriculture (especially development of new cash crops and improved production of wheat, rice and aquaculture)

- health (in particular Hepatitis C, cancer and obesity)

- information and communication technology

- space technology

- socio-economic sciences.

To the STI system, a number of stockholders involved in the advancement of the aforementioned plans could be described in $<$ Fig. 3. $>$ 


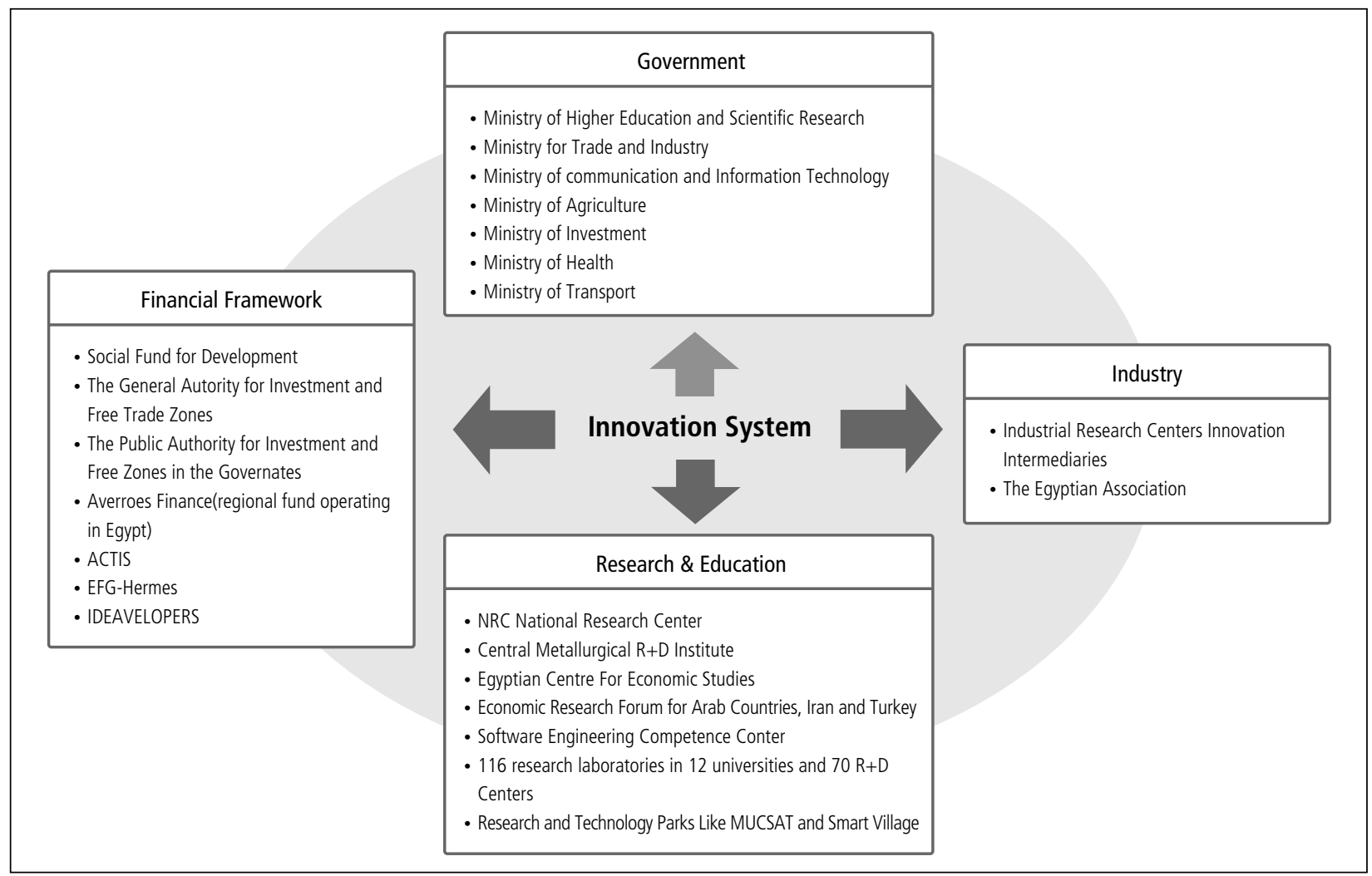

Fig. 3. The main Players in the Egyptian Innovation System

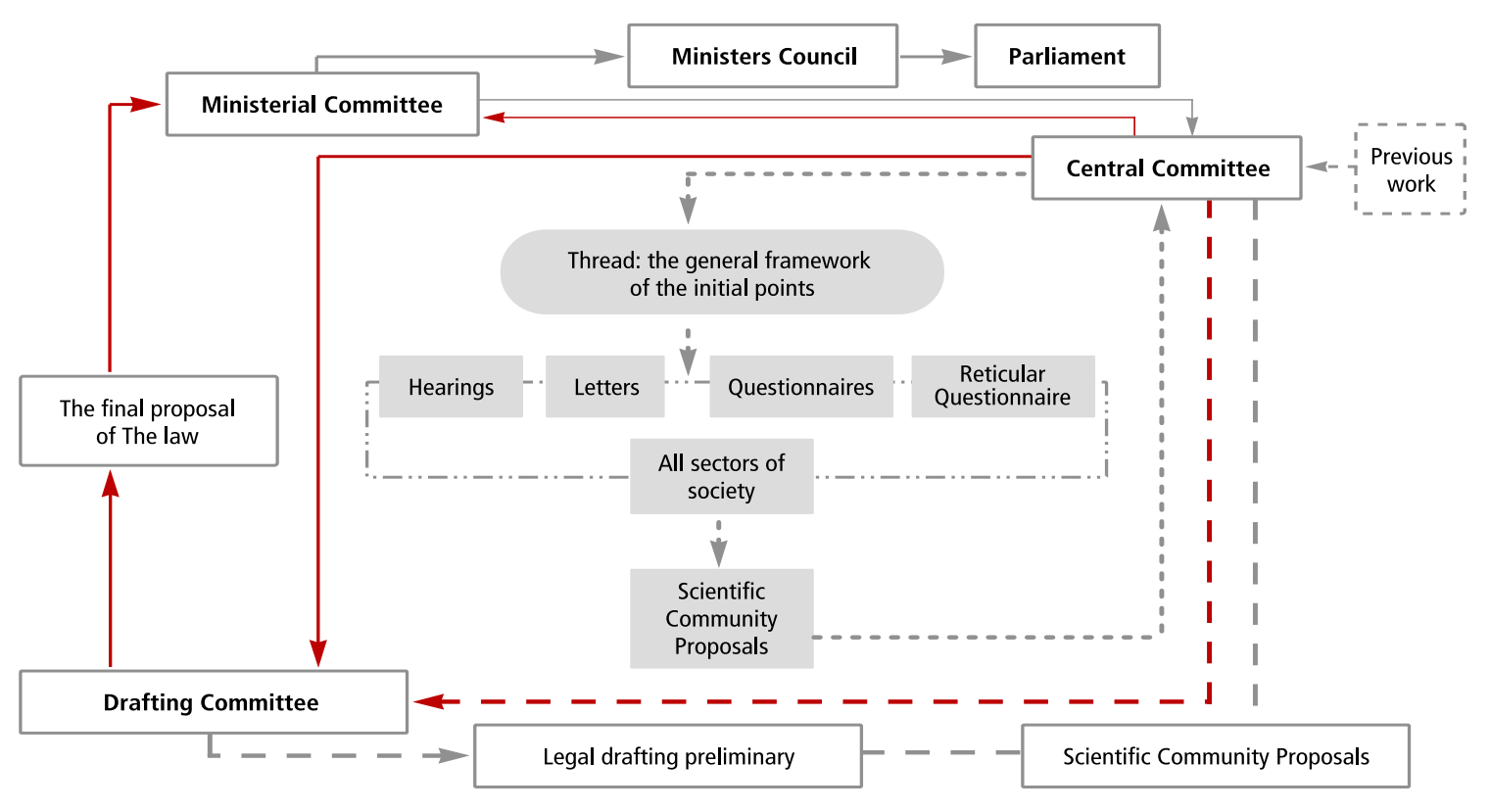

Fig. 4. Schematic Flow Chart of Planning the Rules for Novel Law for Promotion of Scientific Research in Egypt 


\section{Best Practice of Science / Technology Parks}

After affirming the new Egyptian constitution, a new body has been developed with the name The National Council for Education and Scientific Research to replace the higher council for science and technology and act as a big umbrella grouping pre-university, university education and scientific research together.

In spite of the importance of structuring a proper STI Skelton to foster innovation developed by universities and research centers, legislations that encourage investments and consequently contributes in the overall country GDP still the most crucial and determinative issue. For that reason, it is now a prerequisite to draft a law that enjoys theconsent of all concerned parties: the political leadership and parliamentary as well as scientists, investors and industrialists. $<$ Fig. $4>$ illustrates a flow chart.

\section{CONTEXT DIVERSITY OF SCIENCE PARKS}

Over 500 knowledge driven entities exists today in the world in various nomenclature and features such as Science \& Technology Park, Research Park, Technopolis, and Knowledge Park etc. In spite of difference in design and intent these all serve the single purpose to drive technology up in the value chain and help create wealth through science and technology led products and services.

There are striking differences in the motivation of settingup the Science \& Technology Park though they are targeted to institute wider economic and social changes in the region.

Science and Technology Parks have emerged beyond physical infrastructure driven R\&D led new businesses to innovation led economic development instrument.

After the Egyptian revolution, the economy needs to find new outlooks to skip the ceasing period in order to face the Egyptian's dreams and hope. The government in new Egypt still has the willingness to support creating numbers of science and technology parks, creating encouraging environment via new regulations to support investors in the field off science and technology. The large numbers of graduates with an emerging interest in business to establish high value products and services is an additional factor favouring STPs' development. It is suggested that the science and technology park development programme in Egypt should emphasize links between research and production. One strategy to achieve this is to locate high-tech industrial parks next to the proposed science and technology parks so that the option exists to first attract industrial plants to create an agglomeration of industrial activities. It is therefore recommended that this strategy is adopted for the development of the initial science and technology parks in Egypt. This is suggested because of the need to create industrial activity as a pre-cursor to hightech development.

In 2007, a delegate from UNESCO with experts from the World Technopolis Association (WTA) visited Egypt within a framework pilot project supported by UNESCO to identify the most ready place to establish STP in Egypt after the success of the smart village (yet dedicated for IT and telecommunication services). After many visits to Cairo University, National Research Centre, Alexandria University they have drafted a report on the most suitable science and technology hub to develop high technology based products. The report identified City for Scientific research and Technology Applications (formerly, Mubarak City for Scientific Research and Technology Applications MuCSAT) as the most promising-most advanced of the current science and technology parks in Egypt.

It was suggested that the proposed business incubation services should provide technical assistance including supervising and consulting activities to cover the various request from SMEs in SRTACity and its catchment area.

A number of programmes in, for example, Korea and the UK have been developed in stimulate demand by industry for knowledge through which to increase innovation by industry and support industrial development. If such programmes are thought to be of interest it is suggested that these might be reviewed and if appropriate might be deployed in a relevant form in an Egyptian context. Specific details are not set out in this report as these are quite detailed and would need careful review before they could be made 'portable;' to other economies.

\section{EXAMPLES OF EGYPTIAN STPS}

\subsection{City for Scientific Research and Technology Applications (SRTACity)}

In 1991 the government of Egypt has allocated land and money for constructing the first Egyptian Science Park in the northwest coast of Egypt to carry the name of "Mubarak City for Scientific Research and Technology Applications"; renamed after revolution as City for Scientific Research and Technology Applications (SRTACity). At the beginning 100 acres were allocated in the industrial area of New Borg El- 
Arab City near to Alexandria in which about of $40 \%$ of the Egyptian industry take place. Industrial categories of New Burg El-Arab City could be distinguished as follows: paper and wrapping industries (15\%), engineering and constructing (20\%), plastic (15\%), garments (10\%), wood (7\%), food and pharmaceuticals (33\%).

According to the urban structure analysis, there are many strengths of New Burg El-Arab such as: westward ability for urban growth, simplicity and flexibility of the city structure allow for adjusting urban form, efficient hierarchy of road network, all major arterials and collectors are paved, industrial developer area provides potential for exporting industries, accessibility to city districts and industrial zones enhanced by passenger and freight railroad provision and regional public transit (bus) service. Many opportunities for the city include the city regional location enhances its competitiveness, city regional location provides potential for economic independency and multi-sector economic base, connectivity via international and coastal roads, and passengers and freight railroads, accessibility via the airport and Alexandria marine port and land suitability for construction.

On environmental issues: the city has mild weather and location on a high plateau (30-60 meter over Sea Level), abundance of sunshine time and wind velocity, air quality still within acceptable limits, city is relatively clean and no garbage littering is observed.

Creative environment in New Burg El-Arab City is developing rapidly, especially in the presence of a motivated research center (City for Scientific Research and Technology Applications) and a university like Egyptian-Japanese University for Science and Technology.

SRTACity was established to realize the vision "to develop technology based economy serving different areas of human life." SRTACity aims to:

1. Develop centers of scientific excellence to serve both economic and social developments of the Egyptian society.

2. Develop Central Laboratories Core Facilities to serve for consultations, training and solving problems of the industrial sector.

3. Inspire research proposals to achieve the investment plan (previously submitted to theministry). Fields of interest are: Biotechnology, Information Technology, Advanced Technology and New Materials as well as Arid land cultivation.
4. Attract private sector with innovative ideas to implement their insights in the most suitable form: Technology Based Incubators (TBIs), or Spin-offs in the fields of biotechnology, informatics and materials science.

5. Cooperate with different national and international institutes and organizations in the various areas of technology.

Since 1991, the Egyptian Ministry of Scientific Research (MOSR); through the National Research Center (NRC); started to build up the scientific human resources by establishing a rigid selection program to nominate potential candidates to start their training in different fields like biotechnology, material sciences and New and renewable energy. This step was established through $30 \mathrm{PhD}$ scholarships funded from the German government represented by the Ministry of Scientific Research and Technology (BMFT) and 4 PhD scholarships from university of Georgia, USA, where the research titles was concentrated on the transfer of modern technologies of applications serving different areas that have a great impact on the Egyptian industry.

Scholars continued their progress and obtained their $\mathrm{PhD}$ degree, while started to return back home 1997. At that time, the new buildings of two institutes were still under construction, while only one building gathered both administration and capacity building center in west Alexandria district was located. It was actually a great opportunity to start something as important as the science itself, which was to install laboratories properly and making it equipped with necessary instrumentation to carry out research at the same level as learnt in different European and American schools. That was the first step in transferring knowledge with the guidance of welldesigned vision.

According to the presidential decree 1993, twelve institutes and technology centers wereplanned to be included in SRTACity;

- Genetic Engineering and Biotechnology Research institute (GEBRI)

- Informatics Institute (IRI)

- Advanced Technologies and New Materials Research Institute (IATNM)

- Technology Capabilities Development Center (TCDC)

- Arid Lands Cultivation Research Institute (ALCRI)

- Environmental and Natural Resources Research Institute (ENRRI)

- Laser Research Institute (LRI)

- New and Renewable Energy Research Institute (NRERI) 


\section{Best Practice of Science / Technology Parks}

- Fine Chemical Research Institute (FCRI)

- Pharmaceutical and Fermentation Industries Development Center (PFIDC)

- Small Scale Industrial Development Centers (SSIDC)

- Engineering Industrial Development Center (EIDC)

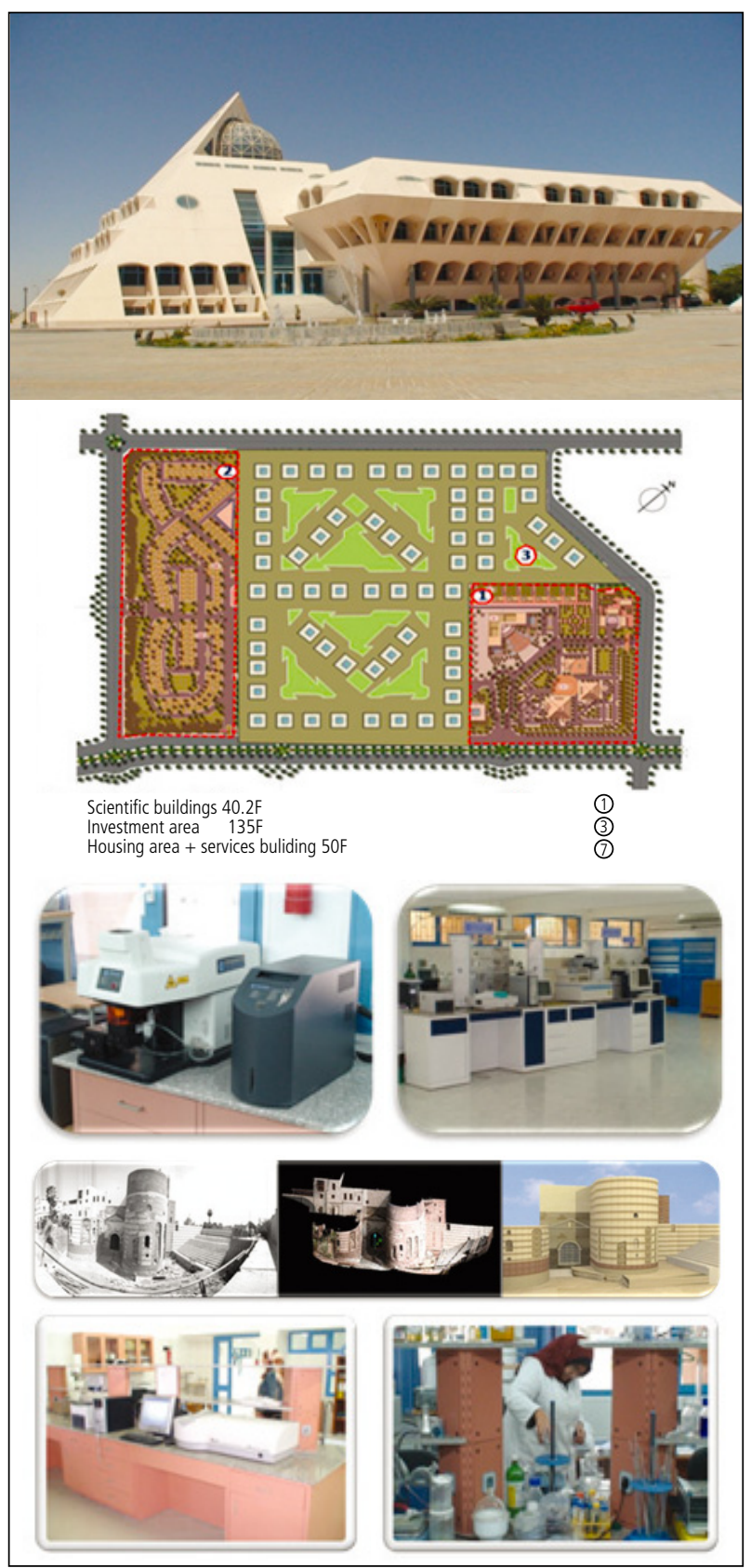

Fig. 5. Master Plan and some Views of SRTACity Laboratories and Projects
SRTACity is structured into three distinct divisions: R\&D institutes, Core facilities and Investment zone. These divisions are to capitalize knowledge based industries engaged in the sectors like e.g., Biotechnology; Nanotechnology; Information technology; Environmental technology; Water treatment and desalination; Food and agricultural technologies; New and Renewable energy and Culture Heritage. It is evident that SRTACity intends to strike a balance between domestic priorities and international opportunities.

\subsubsection{Leveraging existing infrastructure of SRTACity}

a. R\&D institutions

- The four flagship institutions have been created

- Genetic Engineering and Biotechnology Research Institute (GEBRI),

- Informatics Institute (ITI),

- Advanced Technologies and New Materials Research institute (ATNMRI),

- Arid Land and Agriculture development Institute (ARADI)

- In addition to, Technological Capabilities Development Center (TCDC) has been operating at Dekhela as off-site campus.

- These R\&D institutions are engaged in high-end research and developed prototypes and

- Acquire patents having commercial value, which can be available for start-ups. The revenue plan of each institution is to avail grants support from national and international donors largely. Private sector driven commissioned R\&D is yet to take off.

b. Core Facilities

The facilities common and cardinal to support the functioning of these institutions are available, such as

- Wet laboratories Facility.

- Central Laboratory for Services and Environmental Assessment at GEBRI which has accredited the ISO 17025.

- Central Laboratory at ATNMRI - It can conduct and provide following scientific services viz., Elemental Analysis of Materials, Physical and Chemical Characterization of Materials, Micro and Crystalline Structure of Materials, Mechanical Characterization of Materials.

- Semi Industrial Scale cGMP Pilot Plant - This unit was designed to serve the production of new pharmaceutical products and some industrial enzymes and/or development of some existing products. 
- Pre-clinical regional Center

- Engineering Workshop

- Well calibrated Field trial Plots

- Incubators

- Training facility

- Window for technical consultancy

c. Investment zone - Master Plan has been developed and Expression of Interest has been issued to attract investment in the Zone. In accordance with SRTA-City, the Investment Zone also identified the following sectors such as Biotechnology, Biopharma, Nanotechnology, IT and Renewable energy. The support towards SME's will be prioritized.

The Government of Egypt has made this investment in creating SRTA-City to promote the location as ideal destination for knowledge based industries. It aims to cater both the domestic industries mainly to enhance the quality through better scientific and technological intermediation and also to attract investment from outside the country considering the unique geo-political proposition of Egypt.

It is therefore strategic to enhance the utilization of the current facilities both in terms of physical infrastructure as well human resources engaged in the Park.

City for Scientific Research \& Technology Applications intends to bring in investment both from national/local as well as internationally in the form of new businesses in the identified sectors based on initial scoping. It further intends to emerge as a 'Lighthouse' in the region where it steers science \& technology led economic development to start with in Egypt and eventually in the region.

The challenges to be addressed are as follows:

a. Optimal utilization of already created infrastructure: The current infrastructure has been created based on the initial market research and opportunity scanning. It is evident from the fact the current utilization patterns of these facilities demonstrate sub-optimal usage leading to challenges both in terms of positioning vigorously as well as assessing the changing trends in the science and technology driven knowledge markets.

b. creating the right perception/image: New Businesses/ investment aspire to be in SRTA-City as it is 'the destination' for science and technology led business.

c. benchmarking the process for performance delivery:
Creating the appropriate 'character' of the Park, which brings in uniqueness in terms of services offered, quality ensured, share value increased and governance delivered, confidence installed within enterprises.

d. identification right mix of sectors: Current and future market driven assessment of the potential of high-end science and technology sector so that SRTA-Citywill have the 'edge' over other competitors in the region in terms of its readiness to address emerging opportunities in sunshine sectors and also to provide business directions to results coming out of blue sky research.

e. appropriate differentiator: World-class physical infrastructure, favourable ambience in the form of area development through master planning, connectivity and investment friendly financial packaging etc., are most common offer of the leading Science \& Technology Parks in the region. It is henceforth evident that 'the offer' to business/entrepreneurs needs to be unique and innovative so that value proposition has the clear edge over the competitors.

f. significant contribution to GDP Science \& Technology Park model would not provide mass employment. It being very niche and high-end knowledge dependent, the content that holds promise to convert into big spinoffs and the size of investment would be the determining factors in generating high-end employment and wealth in the economy it operates. Quality human resources would be one of the most critical factors in realizing the potential to conceivable outputs.

The opportunities existed currently need to be harnessed,

- Favorable strategic enablers: Proactive and robust Science \& Technology Policy, stable Government and smooth reform functioning, pragmatic human resources development plan and credible geopolitical identity within international communities will help Egypt in enabling STI towards substantial investment.

- Catchment strength: SRTA-City is situated in Borg el Arab region; it houses 40\% of the country's industry. It is therefore expected that SRTA-City will encatch this favorable local conditions effectively. Being strategic geo-politically like proximity to Europe and as gateway to Africa will provide significant opportunity to businesses in the Park besides traditional existing markets.

- Strategic geo-political axis: Strong and strategic relations with developed economies and growing clout in 
regional development will proffer opportunities to shape up and participate in the regional economies. Egypt has assumed the chair in COMESA that will provide sufficient leadership strength in shaping up science and technology based business in Africa as well. Egypt has been able to keep them away from the volatility of the Arab world significantly and that wouldact as confidence builder to investors.

The intent to develop SRTACity as an ideal investment destination in science and technology led knowledge business (manufacturing as spin off will be taken care of outside the Park through the network of economic zones spread over the country designed on the basis of competitive advan- tages) draws its strengths from the current infrastructure, catchment opportunities as well ability to address the challenges effectively.

In order to realize the "intent", an intervention is conceptualized. The purpose being to develop SRTACity as the most preferred destination for investment in science and technology led enterprises, which provides fundamental basis for manufacturing and processing of processes and products in the identified field of Biotechnology, Materials Science, IT and arid zone agriculture, will be guided by the principles of "re-positioning a institution".

The Framework to be followed to carry out the re-positioning intervention would be likewise.

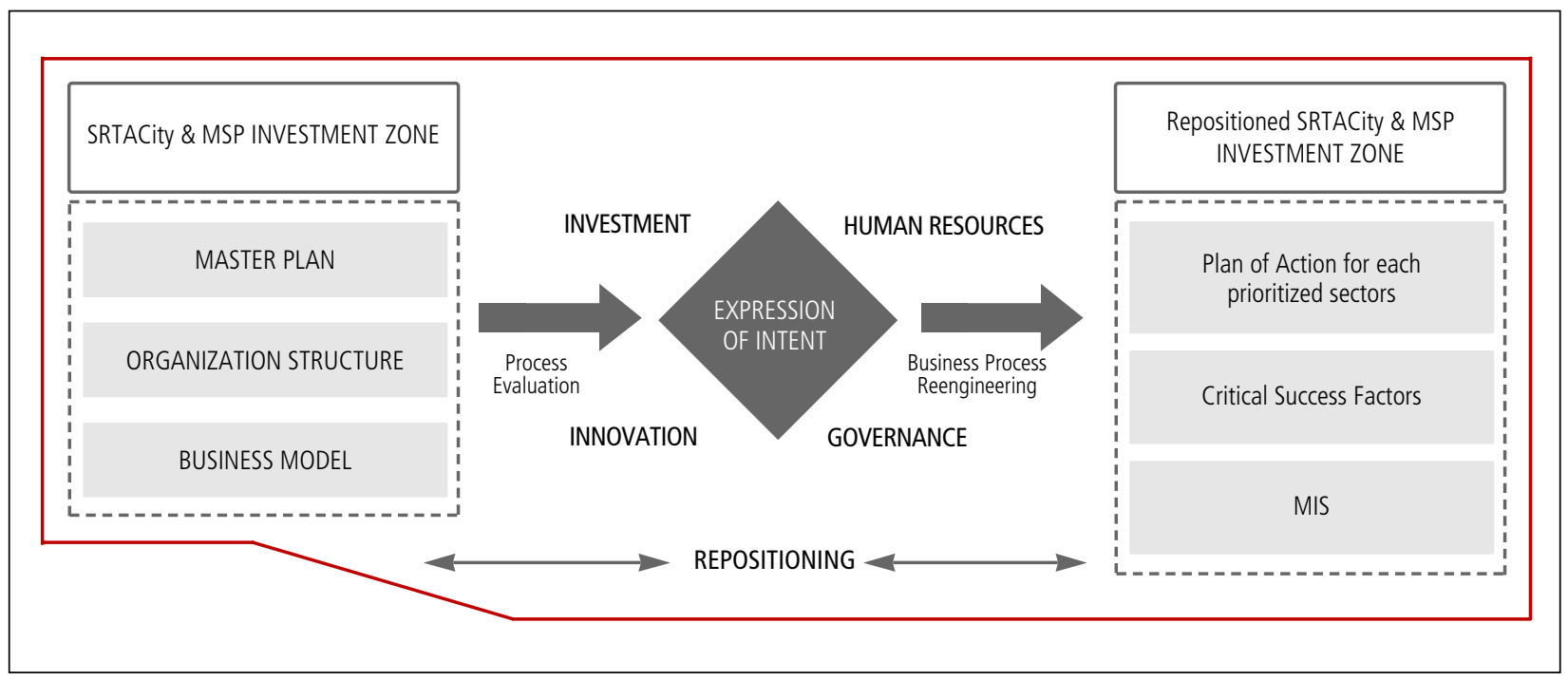

Fig. 6. Master Planning for Repositioning City for Scientific Research and Technology Applications to have an Impact in Egyptian Economy

\subsection{Smart Village in Cairo}

Smart Villages Company (SVC) was founded in November 2001 as a Public-Private-Partnership (PPP) investment with a mandate to establish and manage a branded chain of Technology cluster and Business parks as well as variety of other products and services available here (link to our brands page). We specialize in the establishment and management of communities through innovative thought and practical work. The multipurpose ecosystems are built on quality, collaboration and trust to the satisfaction of all stakeholders. The main vision is to become leaders in creating and operating high end multipurpose human ecosystems and the vision is to create and manage all kinds of communities using innovative thoughts and practical work.
In 2011, Smart Village Egypt is seen as the go to location for hundreds of reputable multinational and local corporations that are looking for a business base in Egypt. Already Providing its customers with a hassle free business environment, Smart Village Egypt $<$ Fig. $7>$ is expected to become the focal point for over 500 corporations, that host over 100,000 employees, conducting their business from 100 operational buildings; as it reaches its completion, Smart Village Egypt will be able to provide 1,000,000 $\mathrm{m}^{2}$ of luxurious office spaces. A fully operational CIT cluster and business park that accommodates multinational and local companies, governmental and financial organizations, educational institutions and research \& development centers all of which share 


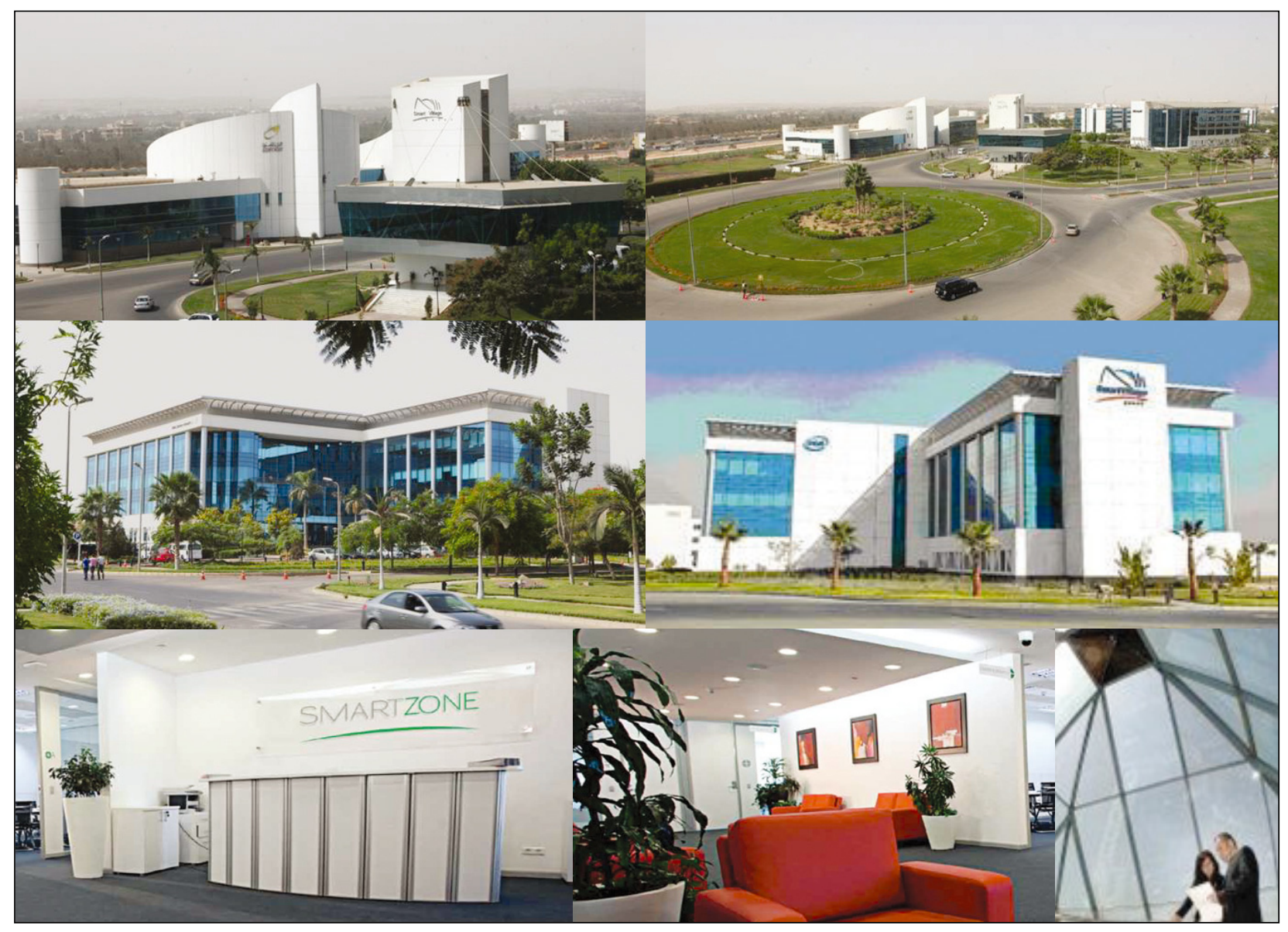

Fig. 7. Some External and Internal Views from Smart City in Cairo

the sophisticated state of the art infrastructure. Smart offices in new franchise are created to accommodate the increasing number of business entities demanding smart buildings to host their business. A green business building, based upon architectural and environmental best practices, and equipped with the latest infrastructure and technological devices, creating a hassle free business environment, and flexible offices suiting the different needs of local and international companies.

\subsection{Technology Valley in Ismailia}

In the framework of the national mega project planned by the state in all fields, the Technology valley has been established as one of big projects that aim at bringing about a new constructional community relying basically on the modern hitech industry to keep up with the advanced comprehensive development $<$ Fig. $8>$. The Strategic Objective of establish- ing the project is to make Egypt a Technology producing and e porting country through establishing a broad productive base working in this field. The project (16500 Acres) is Located in Ismailia governorate. IT is Located Approximately $10 \mathrm{~km}$ from Suez Canal and Ismailia city. The main industries of the valley are:

Renewed energy.

Medical industries.

Project for designing and producing computer systems and software and their appliances of all kind.

Electronics and microelectronics.

Communications and satellites industry.

Biotechnology ...... .etc

There are 14 industrial projects in the project, in addition to the approval of establishing Heliopolis University. 


\section{Best Practice of Science / Technology Parks}

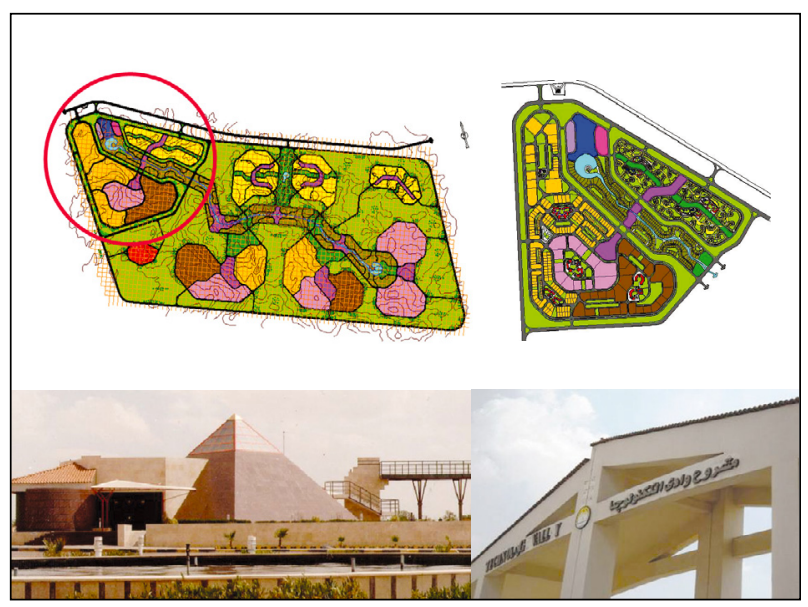

Fig. 8. Master Plan and some Views of the Technology Valley in Ismailia

\section{REFERENCES}

Bond, M., Maram, H., Soliman, A., and Khattab, R.(2012) "Science and innovation in Egypt," Available at http://royalsociety.org/policy/projects/atlas-islamicworld/egypt.

Enrico, S., and Bolisani, E.(2011) "Managing Professions for Knowledge Management," International Journal of Knowledge Management, 61-75.

Hahn, P., and zu Köcker, G.M.(2008) The Egyptian Innovation System, An Exploratory Study with Specific Focus on Egyptian Technology Transfer and Innovation Centres (Berlin, Germany: Institute for Innovation and Technology).

Hall, P.(2000) "Creativity, Culture, Knowledge and the City," Built Environment 30 (3).

Ministry of Housing, Utilities \& Urban Development, Egypt et al.(2012) “BorgEl-Arab New City Strategic Plan,” A Study Prepared By Ministry Of Housing, Utilities \& Urban Development, New Urban Communities Authority (Nuca), New Borg El-Arab Development Agency, General Organization For Physical Planning (Gopp). Available at http://www.ripecap.net/Uploads/ 788.pdf.

Science, Technology and Innovation (STI) System in Egypt(2010), Academy for scientific Research and Technology (ASRT) Book(2010). 